\title{
Análise do Discurso e Ergologia: o sujeito na atividade de trabalho
}

\author{
Discourse Analysis and Ergology: the subject in the work activity \\ Ana Raquel MOTTA* \\ Pontifícia Universidade Católica de São Paulo (PUC-SP/FAPESP)
}

\begin{abstract}
RESUMO: Aborda-se aqui a noção de sujeito da Análise do Discurso, especialmente a partir de textos de Michel Pêcheux da década de 1980, para relacioná-la à noção de corpo-si da Ergologia, conforme postulada por Yves Schwartz. A partir dessa articulação, analisam-se canções de trabalho cantadas por prisioneiros em atividade coletiva de derrubada de árvores no Texas na década de 1960. Tal articulação contribui para que a AD possa analisar o "deslocamento tendencial do sujeito enunciador”, conforme noção postulada por Pêcheux (1981), e também para que a Ergologia possa complexificar sua compreensão de linguagem, considerando a opacidade do discurso. As considerações finais apontam para a ideia de que o debate de normas e valores, conceituado pela Ergologia, pode ser visto como o próprio objeto da Análise do Discurso, uma vez que inclui o interdiscurso e as práticas discursivas.
\end{abstract}

PALAVRAS-CHAVE: Análise do Discurso. Ergologia. Canções de trabalho. Sujeito. Corpo-si.

ABSTRACT: This paper discusses the notion of the subject of discourse analysis, especially from the writings of Michel Pêcheux in the 1980s, to relate it to the notion of "body-self" of Ergology, as postulated by Yves Schwartz. From this articulation, we analyze work songs sung by prisoners in the collective activity of felling trees in Texas in the 1960s. Such articulation contributes to the analysis by the discourse analysis of the "tendential displacement of the enunciator subject" according to the notion postulated by Pêcheux (1981), and also so that Ergology can complexify its understanding of language, considering the opacity of discourse. The conclusions point to the idea that the discussion of norms and values, conceptualized by Ergology, can be seen as the object of discourse analysis, as it includes the interdiscourse and discursive practices.

KEYWORDS: Discourse Analysis. Ergology. Work songs. Subject. "Body-self”.

\section{Introdução}

Estas reflexões sobre o sujeito na atividade de trabalho nascem de uma pesquisa que procura conhecer e compreender o fenômeno mundial das "canções de trabalho", com

\footnotetext{
* Doutorado em Linguística; pós-doutoranda da Pontifícia Universidade Católica de São Paulo (PUC-SP), Programa de Estudos Pós-Graduados em Linguística Aplicada e Estudos da Linguagem (LAEL), e pesquisadora do Centro de Pesquisa FEsTA (Fórmulas e Estereótipos - Teoria e Análise), IEL (Unicamp), e do Grupo de Pesquisa Atelier Linguagem e Trabalho, LAEL (PUC-SP). São Paulo - SP - Brasil. E-mail: anaraquelms@gmail.com.
}

(c) Revista Moara ISSN 0104-0944 (Impresso), n.38, jul.-dez., Estudos Linguísticos, 2012.

Programa de Pós-Graduação em Letras / Universidade Federal do Pará. Todos os direitos reservados. 
ênfase nas manifestações brasileiras ${ }^{1}$. Em princípio, essas canções serão consideradas como as que são cantadas individual ou coletivamente enquanto se trabalha, embora mesmo esta definição provavelmente venha a ser ampliada como resultado da pesquisa maior.

Entendo que uma abordagem adequada deste objeto deve incluir ao menos algumas de suas múltiplas dimensões, na medida em que ele faz parte das práticas discursivas e artísticas dos agrupamentos humanos e também de suas atividades de trabalho. Em minha pesquisa, localizo os cantos de trabalho na intersecção entre linguagem e trabalho, encarando, a partir da Análise do Discurso, a linguagem como sócio-historicamente situada - as práticas discursivas - e, a partir da Ergologia, o trabalho como uma atividade humana - lugar de debates de normas e valores.

Desse modo, considero que o principal desafio do projeto é também seu principal ponto de relevância e interesse: a abordagem transdisciplinar de que lanço mão para compreender o corpus. No caso específico de minha pesquisa, a compreensão de um objeto complexo, multissemiótico e multifacetado como as canções de trabalho demanda tal articulação, para que se possa avançar em relação aos estudos já existentes: basicamente a recolha e "resgate" de canções de trabalho em sua dimensão parêmica e folclórica.

\title{
1 Deslocamentos tendenciais do sujeito
}

Finda esta pequena contextualização do projeto mais amplo, o que apresento neste artigo é um passo inicial com algumas das possibilidades da abordagem discursivoergológica. Escolho iniciar meu percurso por uma citação:

\begin{abstract}
E se a gente se dissesse que nada tem muita importância, que basta se habituar a fazer os mesmos gestos de uma forma sempre idêntica, aspirando somente à perfeição plácida da máquina? Tentação da morte. Mas a vida se revolta e resiste. O organismo resiste. Algo, no corpo e na cabeça, se fortalece contra a repetição e o nada. A vida: um gesto mais rápido, um braço que pende inoportunamente, um passo mais lento, um sopro de irregularidade, um falso movimento, a 'reconstrução', o 'escoamento', a tática do posto; tudo o que faz com que, nesse irrisório quadrado de resistência contra a eternidade vazia que é o posto de trabalho, haja ainda acontecimentos, mesmo minúsculos, que haja ainda um tempo, mesmo monstruosamente estirado. Esse desajeito, esse deslocamento supérfluo, essa aceleração súbita, essa solda fracassada, essa mão que retoma a vida que se liga. Tudo o que, em cada um dos homens da cadeia, urra silenciosamente: “Eu não sou uma máquina!”
\end{abstract}

Certamente os familiarizados com a Ergologia reconhecerão de imediato o discurso dessa sequência. A tentação da morte que seria a perda da saúde, resultado de uma vida totalmente heterodeterminada, nas palavras de Canguilhem (1995 [1966]) em O normal e o patológico. Um gesto mais rápido, um braço que pende inoportunamente, um passo mais lento, um sopro de irregularidade, um falso movimento, a 'reconstrução', o 'escoamento', a tática do posto, tão bem caracterizadas pela Ergologia como "renormalizações", maneiras de realizar uma atividade, sempre diferentes das normas antecedentes.

\footnotetext{
1 Desde abril de 2012 desenvolvo, no âmbito do Programa de Estudos Pós-Graduados em Linguística Aplicada e Estudos da Linguagem (LAEL/PUC-SP), o projeto de pós-doutoramento Canções de trabalho: uma abordagem discursiva e ergológica, supervisionado pela Profa. Dra. Cecília Pérez de Souza-e-Silva e financiado pela FAPESP (Processo No. 2012/00509-8). O presente artigo não analisará o corpus completo de minha pesquisa de pós-doutorado, e sim apenas algumas work songs cantadas por prisioneiros no Texas na década de 1960 (JACKSON et al., 1966).
} 
Renormalizações estas que, por menores que sejam, ocorridas em um irrisório quadrado de resistência, são acontecimentos, mesmo minúsculos.

No entanto, este trecho que citei, de discurso tão familiar para a abordagem ergológica, está em um artigo de um filósofo bastante conhecido pelos analistas do discurso. Trata-se de uma citação retirada de Só há causa daquilo que falha ou o inverno político francês: início de uma retificação, de Michel Pêcheux, publicado pela primeira vez em 1982, introduzido nas edições inglesa e brasileira de Semântica e Discurso como o Anexo III.

A citação é trecho da autobiografia de Robert Linhart, publicada na França em 1978, com o título L'établi. Esta obra ganhou, no Brasil, o título de Greve na Fábrica. Pêcheux, neste ponto de sua produção intelectual, pouco antes de sua morte, fazia uma retificação de parte do que escrevera antes, ou, nas palavras de Denise Maldidier (2003), historiadora e participante da Escola Francesa de Análise do Discurso, uma "desconstrução domesticada". Nos últimos textos de Michel Pêcheux, vemos surgir uma valorização do "acontecimento", e, consequentemente, uma rejeição de algumas teorizações anteriores da Análise do Discurso que haviam desconsiderado as resistências dos sujeitos. Assim sendo, nessa fase Pêcheux abandona o metadiscurso sobre as posições enunciativas referentes a um exterior ideológico e passa a dar atenção ao que ele chama de "deslocamento tendencial do sujeito enunciador", conforme noção presente no texto introdutório de Materialidades Discursivas (colóquio realizado em 1980; PÊCHEUX, 1981, p. 9).

Portanto, esses sujeitos conceituados na chamada terceira fase da Escola Francesa de Análise do Discurso não são, nas palavras de Maingueneau, "ceras moles que se deixariam 'dominar' por um discurso todo poderoso” (2005 [1984], p. 53). Quando ouvimos, ainda hoje no Brasil, esta interpretação do trabalho de Pêcheux - e, curiosamente, esse posicionamento pode vir tanto de seus opositores como de seus supostos seguidores - penso que vale para Pêcheux aquilo de que ele reclamou a respeito da recepção da obra de Althusser. Cito Pêcheux:

\footnotetext{
[...] os Aparelhos Ideológicos do Estado eram lidos - massivamente, e pelas diferentes partes interessadas - como uma intervenção puramente teórica, mais precisamente como uma tese funcionalista, seja para reproduzi-la, seja para condená-la. E alguns ousariam ainda hoje - a despeito de todas as retificações de Althusser, das quais simplesmente não se considera a existência - ir até o fim afirmando que o "althusserianismo" é um pensamento da Ordem e do Mestre, que se institui por uma dupla circunscrição: da História (enclausurada na reprodução) e do Sujeito (reduzido ao autômato "que anda sozinho") (PÊCHEUX, 1997 [1982], p. 296-7).
}

Mais adiante o autor continua, em sua autocrítica: "Levar demasiadamente a sério a ilusão de um ego-sujeito-pleno em que nada falha, eis precisamente algo que falha em Les verités de la palice”. (PÊCHEUX, 1997 [1982], p. 300).

Que os críticos de Pêcheux e da Análise do Discurso de matriz althusseriana não considerem a existência de suas retificações é fato explicável pelo conceito de interincompreensão regrada, de Maingueneau (2005 [1984]). Lê-se o que Pêcheux diz como um simulacro de suas posições, o que torna a teoria facilmente criticável. No entanto, que seus supostos seguidores realizem e reproduzam esta leitura reducionista, é fato de não tão imediata explicação. Uma hipótese talvez seja dada por Indursky (2011). Embora a autora estivesse se referindo ao conceito de "formação-discursiva", estendo-o, por minha conta e risco, para o de "sujeito assujeitado": "Não creio que ainda seja possível, nos dias de hoje, trabalhar com uma FD fechada e homogênea. Diria mais: nem 
mesmo é desejável o fechamento de uma máquina discursiva, embora seja muito mais fácil trabalhar dessa maneira” (INDURSKY, 2011, p. 89).

De todo modo, o teórico não é o dono de sua teoria, e todo leitor tem o direito de preferir uma formulação à outra, mesmo que seja uma versão anterior e abandonada pelo autor. Para mim a escolha está clara: aceito as retificações de Pêcheux e procuro o “deslocamento tendencial do sujeito enunciador”, embora não vá, em minhas pesquisas, recorrer à psicanálise para compreender este sujeito, conforme caminho indicado pelo próprio Pêcheux e reafirmado por alguns autores contemporâneos (cf. FONSECA-SILVA (2005); LEITE (2005); OLIVEIRA (2010), dentre outros).

\section{O corpo-si}

Mas o sujeito da terceira fase da Análise do Discurso também não é um retorno ao Sujeito pleno e consciente, que controla a produção, a recepção e o sentido de sua enunciação. Esse ponto central para a compreensão dos fatos discursivos, a dimensão e o lugar dos sujeitos, segue como pouco especificado para a Análise do Discurso. Há aqui um aspecto em que penso que a Ergologia pode contribuir, através do conceito de "corpo-si".

A Ergologia é uma abordagem interdisciplinar desenvolvida originalmente na França, ao longo dos anos 1980 e 1990, para conhecer e intervir nas situações de trabalho. Parte de conquistas da Ergonomia da Atividade francesa - por exemplo na constatação de que o trabalho prescrito nunca é o trabalho realizado - para elaborar conceitos filosóficos que permitam olhar para a atividade humana. Para explicar o que é o corpo-si, conceito que, creio, pode ser proveitoso para entendimento do sujeito das práticas discursivas e de trabalho, abordarei um importante estudo ergológico feito por Yves Schwartz, filósofo, principal proponente da Ergologia, para uma situação de trabalho bastante inserida na “Organização Científica do Trabalho” (mais conhecida como taylorismo).

Brevemente apresentarei uma parte da "Reflexão em torno de um exemplo de trabalho operário", publicada como “Anexo ao capítulo 1" do livro Trabalho e Ergologia (SCHWARTZ, 2010a). O taylorismo foi uma tentativa de simplificar ao máximo a atividade humana, antecipando-a e preparando-a totalmente, de modo que o executor não tivesse que pensar. Nos termos da Análise do Discurso, seria uma situação extrema de assujeitamento. O discurso mais conhecido a respeito dessas situações de trabalho é bem representado por Charles Chaplin em Tempos Modernos, de 1936: o enlouquecimento de um operário totalmente assujeitado pela máquina e pelo sistema.

No entanto, em um estudo realizado em uma empresa de montagem de televisores, em 1971-72, os pesquisadores puderam observar os seguintes quadros (reproduzidos a partir de Schwartz, 2010a, p. 38): 
Figura 1 - Comparação entre a atividade prevista e a efetivamente realizada
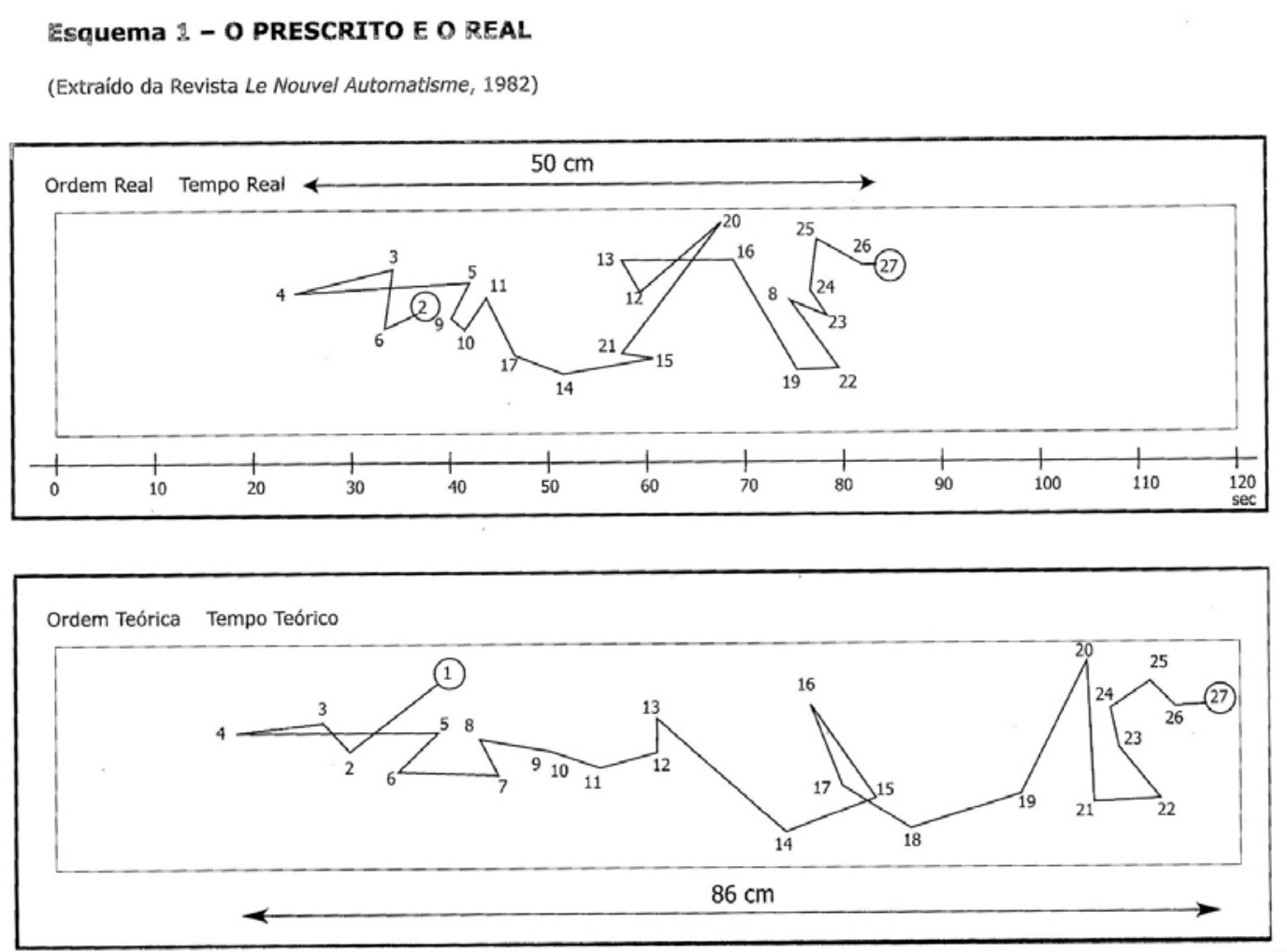

(Fonte: SCHWARTZ, 2010a, p. 38)

A operária observada tinha 27 componentes eletrônicos para pegar em gavetas dispostas estudadamente a sua frente e 27 operações a fazer, para fixar estes componentes em uma placa de braquelite que se locomovia em uma esteira transportadora. Primeira constatação dos pesquisadores: no início do turno, as operárias modificavam a colocação de suas gavetas, sendo que "não existem duas operadoras que adotem a mesma disposição e nenhuma delas respeita a disposição prevista” (SCHWARTZ, 2010a, p. 40).

Esta pesquisa foi realizada por Ergonomistas da Atividade, sob a supervisão de Alain Wisner. O quadro de baixo mostra os movimentos prescritos e o de cima mostra os efetivamente realizados. Os movimentos realizados pela operária neste dia não seguiram nem a ordem nem o tempo do que fora prescrito pela organização científica do trabalho, e o resultado foi que a atividade foi realizada em um tempo e espaço menores.

Yves Schwartz considera que esta pesquisa é bastante importante para a compreensão da atividade de trabalho, principalmente porque, se em uma situação de extrema prescrição invariavelmente houve mudanças, em situações menos controladas certamente também as há. Schwartz estabelece, então, quatro proposições, importantes para a Ergologia:

Primeira proposição: há distância entre o trabalho prescrito e o trabalho real. O esquema apresentado ilustra uma característica universal da atividade humana: nunca o efetivamente realizado é igual ao anteriormente pensado.

Segunda proposição: essa distância, postulada na primeira proposição, está sempre a ser introduzida na história, impossível de ser totalmente prevista. O conteúdo da distância é sempre parcialmente ressingularizado, mas impossível de ser previsto.

Terceira proposição: não existe uma única racionalidade no trabalho. O esquema proposto pelo engenheiro que pensou a atividade dessas operárias é racional, mas invivível. 
Mas o esquema efetivamente realizado também é racional. A entidade que raciocina é o corpo-si:

[...] quem faz a gestão desta distância é a atividade de uma entidade um pouco enigmática que eu chamo de "corpo-si”, alguma coisa que atravessa tanto o intelectual, o cultural, quanto o fisiológico, o muscular, o sistema nervoso [...]. Simplesmente, isso assinala a dificuldade de pensar o sujeito da atividade, porque não é nem o sujeito perfeitamente consciente, nem o sujeito perfeitamente inconsciente, enfim, esta entidade atravessa tudo isso. A atividade remete a isto. (SCHWARTZ, 2010a, p. 44)

Quarta proposição: essa distância remete a um debate sobre os valores e sobre as normas. Se o ser humano nunca realiza exatamente o prescrito, é porque existem outras razões que entram em jogo além das razões pensadas anteriormente para aquele trabalho. Nas palavras de Schwartz: “[...] a pessoa faz escolhas! Ela faz as escolhas, conscientes ou inconscientes, (...) mas ela faz escolhas. Se ela tem escolhas a fazer, é em função de critérios - e portanto em função de valores que orientam estas escolhas. Não se pode escapar disso" (SCHWARTZ, 2010a, p. 45).

Penso que as quatro proposições válidas para toda atividade humana, desenvolvidas por Schwartz, e o “corpo-si” visto dentro desse arcabouço teórico, representam um bom caminho para o estudo do sujeito do discurso, principalmente se consideramos que o discurso são práticas discursivas intersemióticas, de que o corpo participa. Nesse sentido, retomo trechos de minha citação inicial, de Robert Linhart (1978, p. 21): "Mas a vida se revolta e resiste. O organismo resiste. Algo, no corpo e na cabeça, se fortalece contra a repetição e o nada. A vida: um gesto mais rápido, um braço que pende inoportunamente, um passo mais lento, um sopro de irregularidade, um falso movimento [...]”.

\section{Trabalhando e cantando}

Penso poder caracterizar o movimento deste corpo que trabalha, e que ressingulariza o prescrito, como uma prática discursiva. Então temos algo, no corpo e na cabeça, que se fortalece. Parece-me uma boa maneira de considerar as canções de trabalho, por exemplo na situação que apresento a seguir: a derrubada de árvores por prisioneiros do Texas, filmada em documentário² em março de 1966.

Pode-se dizer que poucos sujeitos eram menos livres que esses: negros descendentes de escravos no Texas altamente racista da década de 1960, prisioneiros em uma das mais vigiadas prisões dos Estados Unidos. Forçados ao trabalho de cortar árvores, esses prisioneiros desenvolveram a prática de canções de trabalho dentro da prisão, dando continuidade às canções de trabalho que seus antepassados praticavam nas plantations e, posteriormente, que seus pais e eles próprios praticavam em seu dia-a-dia de libertos.

Os machados se movem compassadamente, o que garante a sobrevivência dos trabalhadores envolvidos na atividade: caso não houvesse o ritmo coordenado, o trabalho de quatro homens cortando a mesma árvore se tornaria bastante arriscado (figura 2). Nesse sentido, há um amalgamento entre cumprir o prescrito (cortar a árvore) e cantar a canção de trabalho, o que se manifesta em um todo indissociável de voz, corpo, mente, físico, indivíduo, coletivo: ou seja, o “corpo-si”.

\footnotetext{
2 Afro-american Work Songs in a Texas Prison. Documentário de Bruce Jackson, Toshi Seeger, Daniel Seeger, Peter Seeger (1966). Disponível em http://www.folkstreams.net/pub/FilmPage.php?title=122. Acesso em: 26 jun. 2012.
} 
Figura 2 - Derrubada de árvores por prisioneiros no Texas, organizados pela canção de trabalho

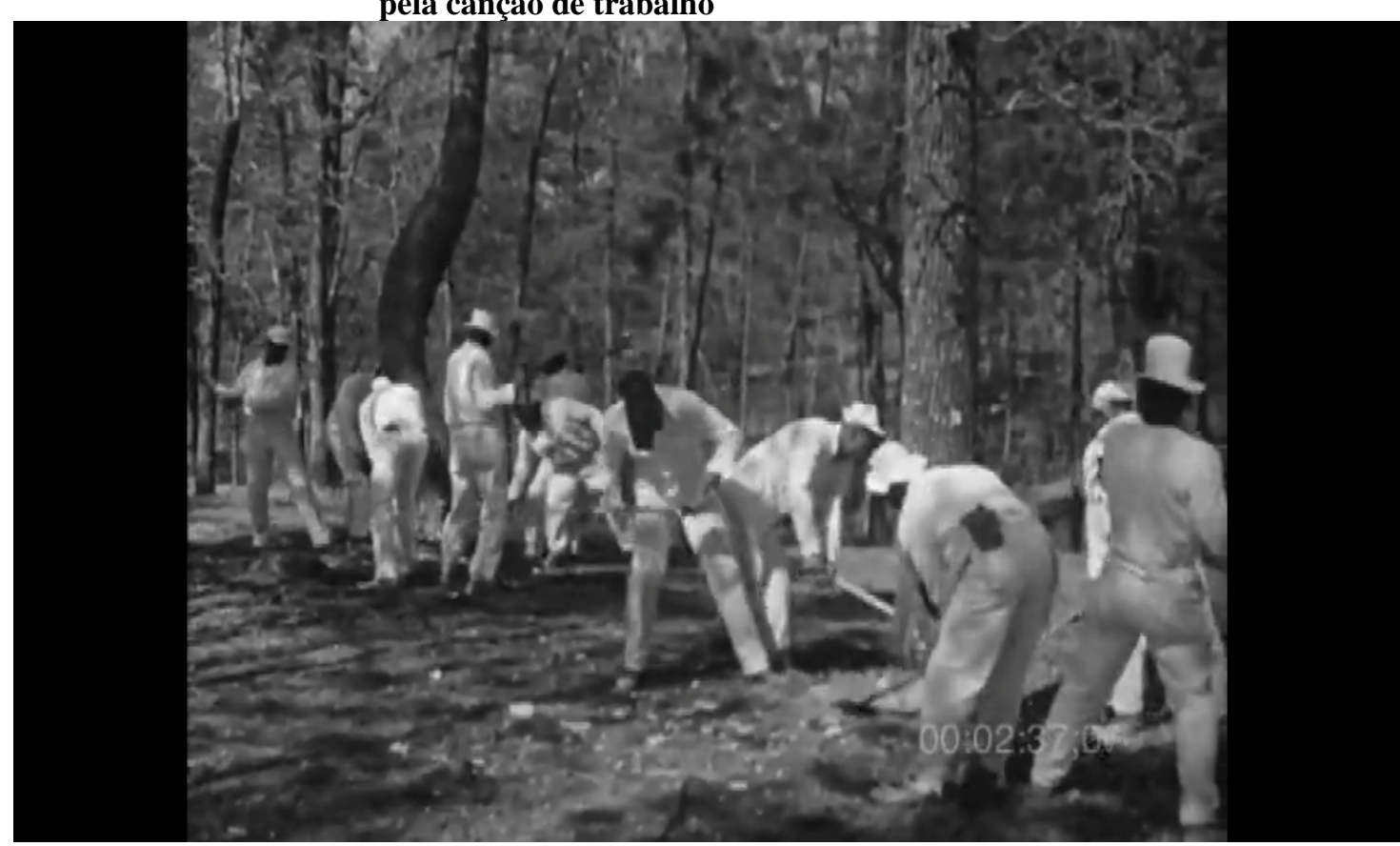

(Fonte: Documentário Afro-american Work Songs in a Texas Prison. JACKSON et al., 1966)

É bastante tocante que os prisioneiros comemorem a queda de cada uma das árvores, como uma vitória da equipe de trabalho (figura 3). Creio que fatos observáveis como este são importantes para complexificar uma visão mais homogênea que poderíamos ser tentados a ter: o trabalho como um fardo e a canção de trabalho como um prazer e um alívio.

Figura 3 - Prisioneiros do Texas comemoram a queda da árvore que estavam cortando

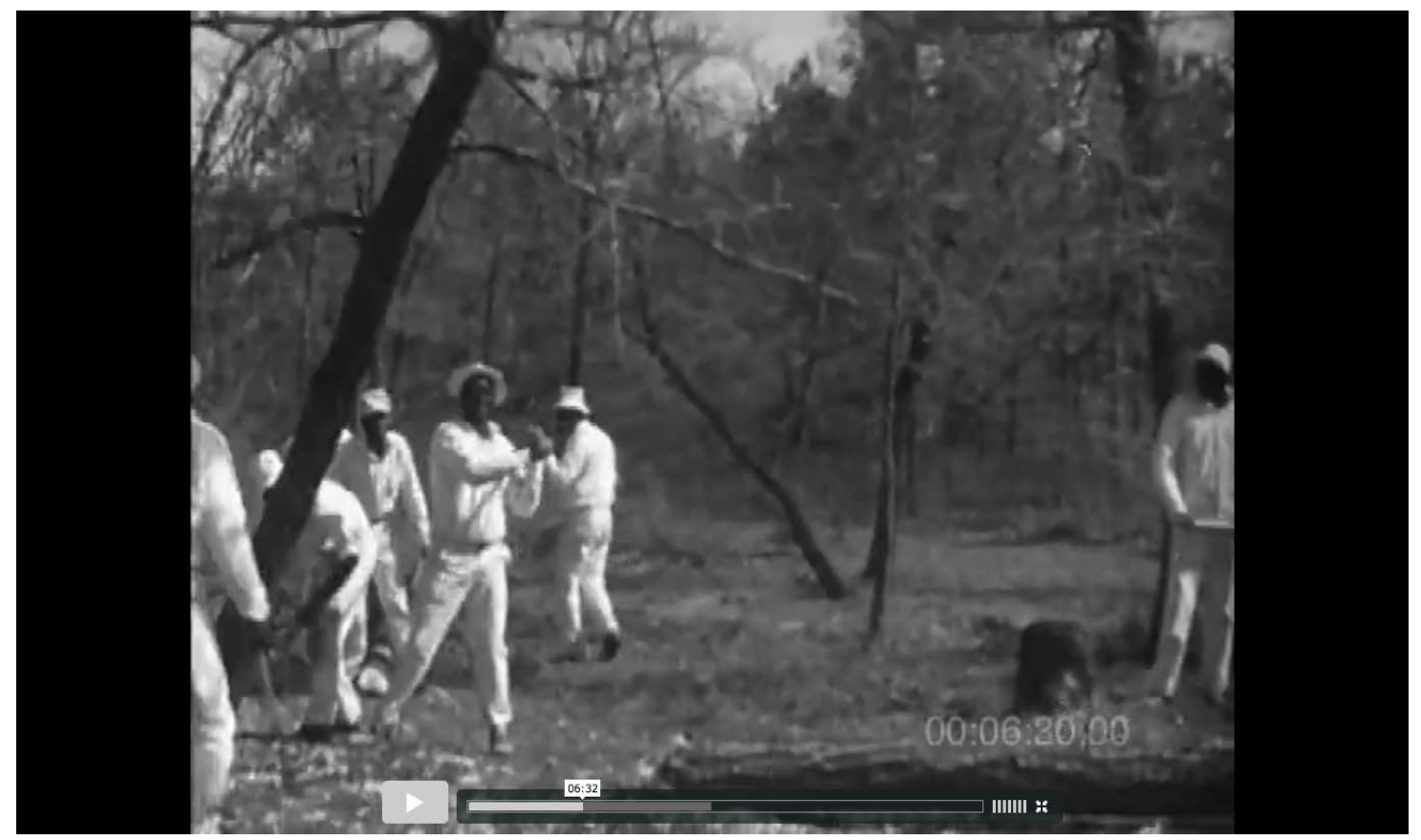

(Fonte: Documentário Afro-american Work Songs in a Texas Prison. JACKSON et al., 1966) 
No entanto, há mais elementos a considerar. Trata-se, certamente, de uma situação tensa. A cena apresenta mais de uma dezena de prisioneiros, homens fortes com machados nas mãos, formando um grupo unido por muitos liames, como, por exemplo, a condição de prisioneiro, a cor da pele, a etnia e os elementos culturais de que as canções de trabalho fazem parte. De outro lado, há o guarda, o único branco, o único montado a cavalo, o representante do Estado e do sistema prisional. A letra da canção de trabalho cantada faz coro à tensão, quando tematiza uma "caçada de urso" e o que aconteceu com o "urso":

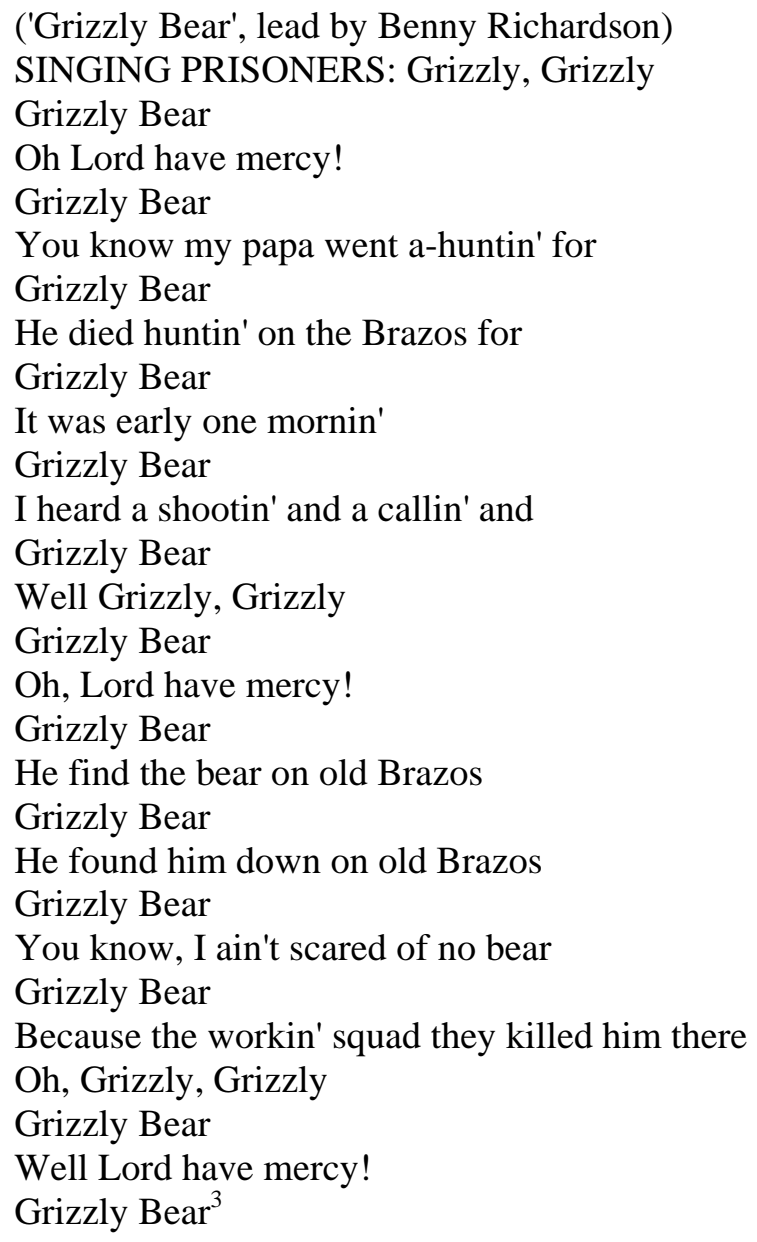

Os cantores se dirigem a Deus (Oh Lord), pedindo piedade. A voz principal (o condutor desse canto responsorial ${ }^{4}$ ) conta uma narrativa: seu pai foi caçar um urso pardo no rio Brazas (o maior do Texas). O urso o matou, mas o enunciador não tem medo de

\footnotetext{
3 ('Urso pardo', conduzida por Benny Richardson)/ PRISIONEIROS CANTANDO: Pardo, Pardo, Urso Pardo/ Oh Senhor tenha piedade!/ Urso Pardo/ Você sabe que meu pai foi a uma caçada de/ Urso Pardo/ Ele morreu caçando no rio Brazos o/ Urso Pardo/ Era de manhã cedo/ Urso Pardo/ Eu ouvi um tiro e um chamado e/ Urso Pardo/ Bem, Pardo, Pardo/ Urso Pardo/ Oh Senhor tenha piedade!/ Urso Pardo/ Ele encontra o urso no velho rio Brazos/ Urso Pardo/ Ele o encontrou embaixo no velho Brazos/ Urso Pardo/ Você sabe, eu não tenho medo de nenhum urso/ Urso Pardo/ Porque a equipe de trabalho, eles o matam lá/ Oh, Pardo, Pardo/ Urso Pardo/ Bem, Senhor tenha piedade!/ Urso Pardo. [tradução minha]

${ }^{4}$ Esta conceituação é de Tinhorão (1988). Trata-se de estrutura comum no canto popular brasileiro, estando presente em diversos outros lugares do mundo. No Brasil, podemos apontar esta estrutura no samba de roda e na capoeira, dentre muitos outros exemplos. Acredito que esta constituição seja relevante para a caracterização dos aspectos individuais e coletivos dessas manifestações culturais e pretendo aprofundá-la em sua relação com a visão ergológica de trabalho.
} 
nenhum urso, pois a equipe de trabalho (em inglês, workin' squad) o mata no mesmo momento e local. No trecho da canção em que a morte do urso é mencionada, os diretores do filme focalizam o guarda, que não havia ainda sido focalizado na cena (figura 4). Tal tomada sugere fortemente a leitura de que há uma relação entre o guarda e o urso pardo da canção.

Figura 4 - Destaque para o guarda montado que vigiava os prisioneiros

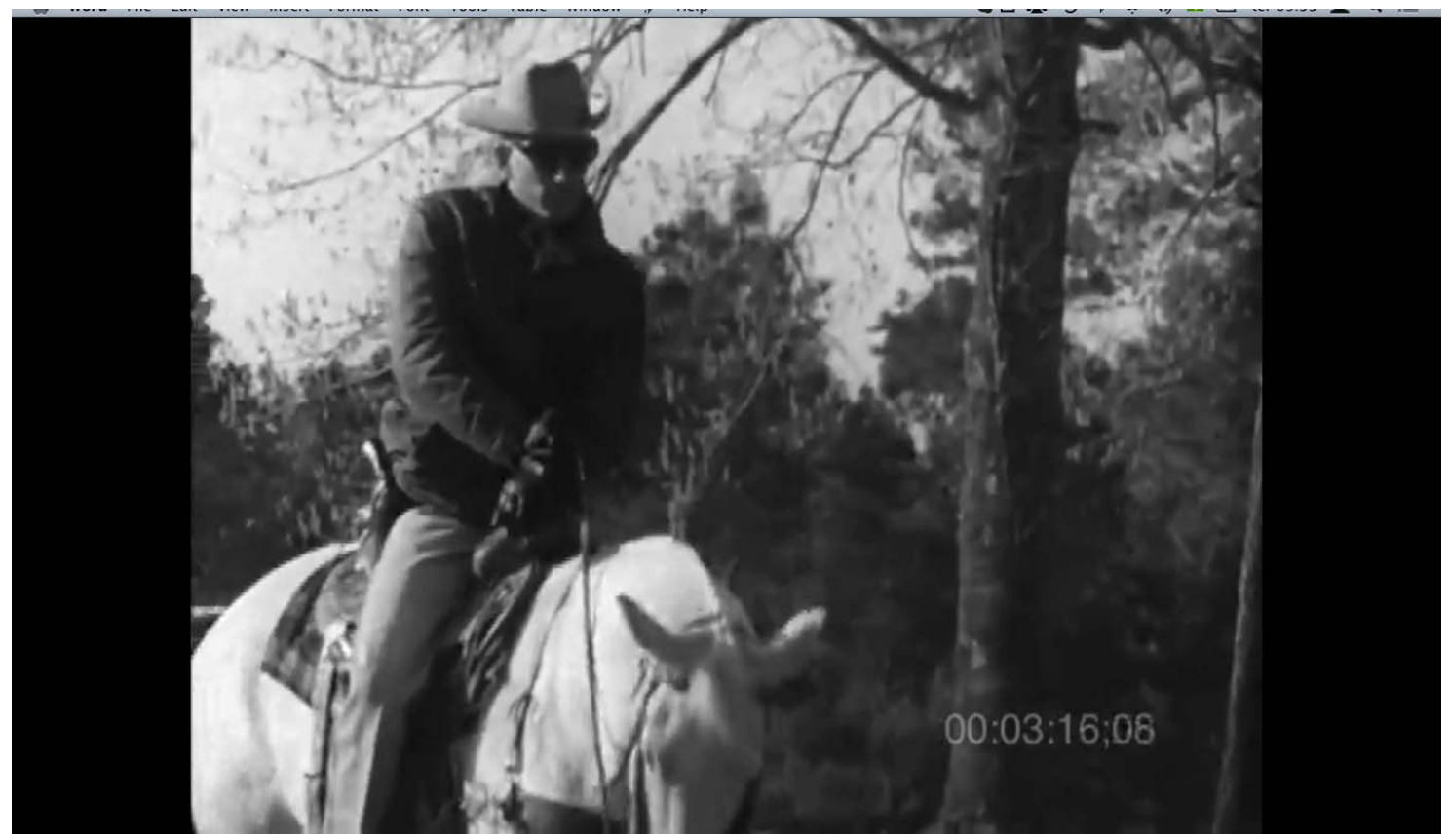

(Fonte: Documentário Afro-american Work Songs in a Texas Prison. JACKSON et al., 1966)

E a atividade continua em aparente normalidade. Os prisioneiros cortando as árvores, cumprindo, de algum modo, as normas antecedentes. A canção de trabalho fortalecendo o ritmo da atividade, e também tematizando o poder da resistência da equipe de trabalho, sempre em prontidão para defender um dos seus contra o “urso".

\section{Considerações finais}

Desenvolvi, aqui, apenas alguns aspectos promissores da abordagem discursivoergológica, em especial a relação que tenho traçado entre o "deslocamento tendencial do sujeito enunciador" (PÊCHEUX, 1981) em suas "práticas discursivas intersemióticas" (MAINGUENEAU, 2005 [1984]) e a noção de corpo-si da Ergologia. Sem dúvida, esta abordagem desloca os conceitos de seus lugares originais, o que não se dá sem consequências que, no momento, se apresentam como limites a serem transpostos pela pesquisa. Apenas para citar duas: a consideração do corpo, bastante frágil em Análise do Discurso e na Linguística em geral, torna-se mais premente. Do lado da Ergologia, torna-se fundamental a passagem da língua - compreendida como lugar da consciência e da organização do simbólico - para o discurso, "trabalho do sentido sobre o sentido, tomados no relançar indefinido das interpretações” (PÊCHEUX, 1990 [1983], p. 51).

Trata-se, portanto, "de se colocar em posição de entender esse discurso, a maior parte das vezes silencioso, da urgência às voltas com os mecanismos da sobrevivência; trata-se [...] de se pôr na escuta das circulações cotidianas, tomadas no ordinário do sentido (cf., por exemplo, De Certeau (1980))” (PÊCHEUX, 1990 [1983], p. 48). 
Creio já ser possível afirmar que as renormalizações, conceituadas pela Ergologia, são "deslocamentos tendenciais do sujeito enunciador", e são sempre, ao menos parcialmente, ressingularizadas, pois, a despeito do que pretendia o taylorismo, "ninguém pode pensar no lugar de quem quer que seja” (PÊCHEUX, 1997 [1982], p. 304).

Lanço aqui a hipótese de que o objeto da Análise do Discurso são justamente os debates de valores e normas, conforme a conceituação da Ergologia, debates estes que fazem da atividade de trabalho um encontro de encontros, pois "dentro do infinitamente pequeno do trabalho, encontram-se os maiores problemas do político, [...] encontramos nas escolhas atuais [...] tudo o que se passa no macro" (SCHWARTZ, 2010b, p. 33). E assim se faz história.

Portanto, cantando, falando, trabalhando e urrando silenciosamente: eis o sujeito das práticas discursivas.

\section{REFERÊNCIAS}

CANGUILHEM, G. O normal e o patológico (1966). Trad. Maria Thereza Redig de Carvalho Barrocas. Rio de Janeiro: Forense Universitária, 1995.

DE CERTEAU, M. A invenção do cotidiano: artes de fazer (1980). Trad. Ephraim Ferreira Alves. Petrópolis: Vozes, 1990.

FONSECA-SILVA, M.C. Materialidades discursivas: A fronteira ausente (um balanço). Estudos da lingua(gem), 1: 91-97, 2005.

INDURSKY, F. Da interpelação à falha no ritual: a trajetória teórica da noção de formação discursiva. In: BARONAS, R. L. (org.). Análise de discurso: apontamentos para uma história da noção conceito de formação discursiva. São Carlos: Pedro e João (2a . edição revista e ampliada), 2011. p. 77-91.

JACKSON, B.; SEEGER, T.; SEEGER, D.; SEEGER, P. Afro-american Work Songs in a Texas Prison (1966). Disponível em: http://www.folkstreams.net/pub/FilmPage. php?title=122. Acesso em: 26 jun. 2012.

LEITE, N. V. de A. Só há causa daquilo que falha. In: Estudos da língua(gem), 1: 77-82, 2005.

LINHARDT, R. Greve na fábrica. Trad. Miguel Arraes. São Paulo: Paz e Terra, 1978.

MAINGUENEAU, D. Gênese dos discursos (1984). Trad. Sírio Possenti. Curitiba: Criar, 2005.

MALDIDIER, D. A inquietação do discurso. (Re)ler Michel Pêcheux hoje. Trad. Eni Orlandi. Campinas: Pontes, 2003.

OLIVEIRA, F. A. Análise do Discurso e Psicanálise: a questão do sujeito. Revista Latinoamericana de Estudios del Discurso - ALED, 10 (2), 2010.

PÊCHEUX, M. O discurso: estrutura ou acontecimento (1983). Trad. Eni Orlandi. Campinas: Pontes, 1990.

PÊCHEUX, M. Ouverture du coloque. In: CONEIN, B. et alii (orgs.). Materialités discursives. Lille: Presses universitaires de Lille, 1981. p. 6-10.

PÊCHEUX. M. Só há causa daquilo que falha ou o inverno político francês: início de uma retificação (1982). In: Semântica e discurso: uma crítica à afirmação do óbvio. Trad. Eni Orlandi et alli. Campinas: Editora da Unicamp, 1997. p. 293-307. 
SCHWARTZ, Y. Reflexão em torno de um exemplo de trabalho operário. Trad. Jussara Brito et alli. In: SCHWARTZ, Y.; DURRIVE, L. (orgs.). Trabalho e ergologia: conversas sobre a atividade humana. Niterói (Brasil): Editora da UFF. (2a . edição revista e ampliada), 2010a. p. 37-46.

SCHWARTZ, Y. Trabalho e Ergologia - conversa entre Louis Durrive, Yves Schwartz e Marcelle Duc. In: SCHWARTZ, Y.; DURRIVE, L. (orgs.). Trabalho e ergologia: conversas sobre a atividade humana. Niterói (Brasil): Editora da UFF. (2a. edição revista e ampliada). 2010b. p. 25-36.

TINHORÃO, J. R. Os sons dos negros no Brasil. São Paulo: Art Editora, 1988.

Recebido em fevereiro de 2013.

Aprovado em abril de 2013. 